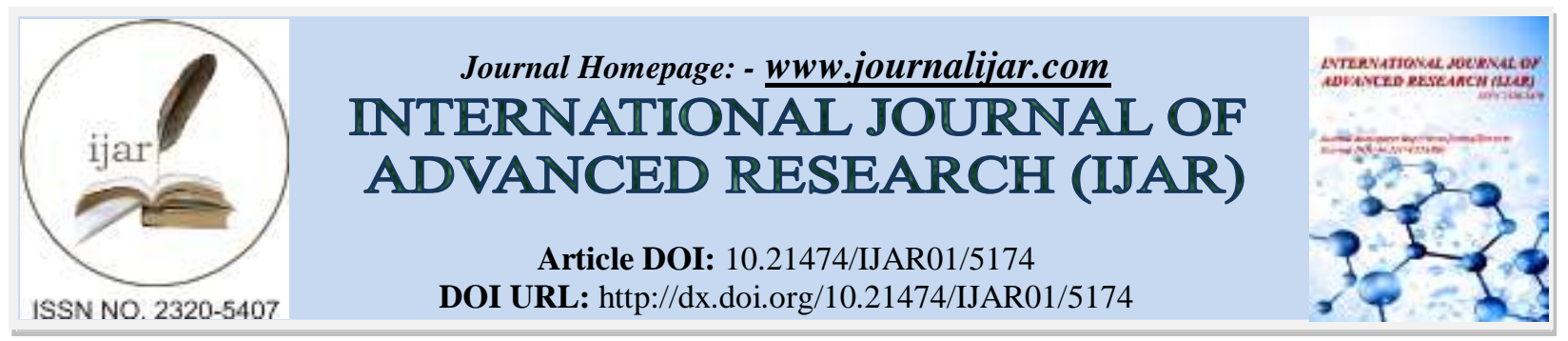

RESEARCH ARTICLE

\title{
THE CHANGE OF PRIVACY CONCEPT OF THE FISHERMAN TRADITIONAL HOUSE TO BE FARMERS HOUSE IN CUSTOM SENTANI PAPUA INDONESIA.
}

\author{
Deasy Widyastomo ${ }^{1}$, Muhammad. Faqih ${ }^{2}$ and Purwanita Setijanti ${ }^{2}$. \\ 1. Doctoral Student, Department of Architecture, Institute Technology of Sepuluh November, Surabaya, \\ Indonesia. \\ 2. Department of Architecture, Institute Technology of Sepuluh November, Surabaya, Indonesia.
}

Manuscript Info
Manuscript History
Received: 14 June 2017
Final Accepted: 16 July 2017
Published: August 2017
$\begin{aligned} & \text { Key words:- } \\ & \text { Habitus, privacy, traditional houses, } \\ & \text { custom Sentani. }\end{aligned}$

\begin{abstract}
The change habitus from fisherman to farmers in the Sentani customary community becomes a phenomenon that causes changes in the privacy of traditional homes, where Bourdieu (2002) 'habitus' is said to be the way people interpret and respond to the environment within the framework of their knowledge, familiar ideas and personal experience habits in a sociocultural context. The change of habitus from fisherman to the farmer of Sentani community becomes the latest of this research is investigating the change of privacy space. The research method used is qualitative research with by doing the interpretation and definition of the three method i.e., reviewing the document history (historical reference in 1903) did a study of past and current conditions (existing). The results showed that change habitus fisherman become farmers on indigenous Sentani revamp concept of privacy at home.
\end{abstract}

Copy Right, IJAR, 2017,. All rights reserved.

\section{Introduction:-}

The diversity of traditional houses in the archipelago have a philosophy and rich in creations-a different architecture than a home with other traditional homes as well as having the feel of high art. As according to the Waterson (1993), the traditional home of diversity shows a wealth of architecture from Sabang to Merauke Archipelago. Privacy is the conception of a certain culture (Altman, 1977). The focus of the study on the concept privacy associated with culture, behavior, the built environment, privacy in residential and other privacy sphere carried out by Altman et al 1981; Altman and Chemers, 1980. Margulis (2003) examines privacy is control over the relationship between the individual and the sociologist; in which they state their limits are limited, and people outside will not bother (Fahey, 1995). In the Razali NHM and Talib A (2013), explains the behavior described by Altman et al. (1981), says there is four elements namely verbal, para-verbal, nonverbal and environment. The environmental behavior of elements put emphasis on personal space, territory and physical environment. The privacy theory is a two-way connection behavior involves people and others including team, group, family and other social unity, which is not done at a certain time. While Abdul-Rahim (2014), the condition of the house lived in urban areas, a new cultural paradigm in the housing and the lack of consideration the creation of visual privacy in the design of housing, the conception of visual privacy and regulation influenced by Malay and Islam as a way of life.

The privacy operates at individual, group and organizational level or institutional but stressed that his theory of privacy applies specifically to Western culture because it is consistent with the social political values of Western democracy. The Privacy should be viewed from the perspective of the culture in question. Privacy in a different 
culture has been translated into different physical levels and responses in the design of the house according to the Westin (1967). The privacy needs in the use of space and how to set privacy is one of the ways in which different cultures, so that the shape of the different houses around the world (Rapoport, 1969). The House is the main setting for privacy and design related attributes act as privacy is important.

The Traditional house in the community of Sentani indigenous has uniqueness and still survive until today. One of the traditional culture as a work of architecture that still survives and has a unique characteristic that is a traditional house situated in the surroundings of indigenous settlements in Sentani Lake. As it is said Hartzler (1976), the community traditionally Sentani living as a fisherman, farmers, and harvesters of sago. The indigenous people Sentani is a homogeneous society that still adheres to the tradition taught ancestor ancestors. One of them can be seen physically from the traditional house of the people in Sentani indigenous. The culture is changing along with the built environment. When the neighborhood was built for homogeneous groups of people that have control over the environment awakened as seen in traditional societies (Rapoport and Hardie, 1991).

\section{Research Methods:-}

Groat and Wang (2002), the research is qualitative interpretation and meaning towards the current situation or progress. Emphasis on the role of the researcher as the main part that is as "objective eyes" from a research tool, and the data obtained by means of observation, a list of open questions, and interview on the real background (natural setting). The research methods used to study the environmental and cultural change have said Rapoport and Hardie (1991) to try to build a foundation of traditional culture and environment through environmental order wakes up from time to time and to identify the core elements of the surviving traditional, change, disappear and new elements. Lawrence (1987) in a Faqih (2005), proposed a study of the comparative on the same type of building types in different communities, to describe the relationship between reciprocal variable architecture, society, and culture in the community. Methods need to be established on a systematic analysis of the spatial buildings and how activities in the space of time travel. Lawrence method combined with model changes of learning according to Rapoport.

The Research procedure using three steps investigation to find changes in the relationship of culture and architecture at a different residence (habitus fisherman and habitus farming) and the transformation of the physical environment in the House. The three steps of the investigation (1). The review the document history (historical reference year 1903) past and previous research studies, and criticism to find the base of the authenticity of the existence of the indigenous community of Sentani; (2) The collecting oral history and collective memory through interviews and observation method to find a variety of opinions, as well as the development of traditional historic homes and the heritage of traditional vernacular cultural life; (3) The direct observation Methods, to increase rehabilitates from research in methods of case studies.

\section{Theory Of Privacy:-}

Habitus is practically intuitive reactions to situations based on experience and is spontaneity without awareness or willingness (Bourdieu, 1990). The working from this perspective, the habitus is a product of history (social experience and education), and yet the process to strengthen themselves can be changed by history, experience, education or training through reflexive. The main concept of habitus said Bourdieu as a factor mediating between social structures and practices. Bourdieu in the context of architecture special meaning to imply that people interpret the built environment shaped and limited by what they know of the background of their own socio-cultural experience as well as their ideas accepted, practice or conditions that prevail in their contextual environment. Bourdieu's idea on the formation of meaning, reveal how human view, past experience or ideas, and their social cultural associations with the built environment, play an important role in the development and transformation of identity architecture. (Bourdieu 2002).

The privacy is the ability of the individual or group to control the types of interaction and to obtain the desired interaction conditions by way of regulating the distance of personal or social distance (Rapoport, 1977). Bates, Chapin, and Guess (in Altman, 1975) define privacy as the need for separateness of the individual from the social environment. This definition is also similar with Sarwono (1992) stating that privacy is the desire or tendency in oneself not to be disturbed, alone. Altman (1975) defines privacy as the selective control of access for yourself or groups. Altman also sees privacy as a central concept of all process management space. The personal space and territory of the constitute the mechanism, when people can set their privacy and distresses (crowding), is the failure to obtain privacy. According to Altman and Chemers(1984) defines privacy as control effectively access to 
emphasize the closeness and openness that leads to the development of human behavior and moral growth (Newell, 1995).

Altman and Chemers (1984), the relationship of culture and physical environment with the public as a physical process which consists of mental activity and behavior. The mental activities include things that happen in the thought of people about what they see, hear, taste, and interpretation of the about the physical environment. It also includes mental activities of trust and positive attitude or negative to the environment. In Altman (1981) and Newell (1995) how to view privacy regulation theory refers to the process of change and adaptation to human development throughout life. Immediacy refers to people who isolate than others and contrarily for person openness trying to be easier to access. According to Westin (1967) cited by McAndrew explained there are four state of privacy: solitude (Solitude), intimacy (intimacy), anonymity (freedom), reserve (reluctance). Solitude shows the description of privacy in General, i.e. the opportunity to split from the others and be free from supervision. Intimacy is freedom along with the others in such limited quantities as a friend. Anonymity is the freedom of being in public areas with no supervised by others. The reserve (aversion) occurs when a person is trying to exile because of the limitations of the other (McAndrew, 1992).

The privacy is not an end in itself but is a process of regulatory change according to the needs and settings. The dialectical process which involves the individual's ability to control the permeability of boundaries they set personal (Altman, 1977). Altman also argued that there are two types of mechanisms regulating the privacy; mechanisms of behavior and the environment. Mechanisms of behavior include verbal behavior and nonverbal and influenced by the sociocultural factors. The people in all cultures involved in the regulation of social relations and behavior mechanisms where accessibility is controlled and perhaps unique to a State of physical, psychological and sociocultural specific. The privacy rule is very important in the process of achievement of privacy when the physical environment does not provide the desired privacy. The need to provide visual privacy for individual families and the community, in General, resulted in the location of the buildings in relation to each other and the placement of the window as depicted by Besim (1986). This also affected the location and specific main entrance, the Division of space in the public domain and private domain and providing a space for parents and children from a variety of gender. Visual privacy also influenced strategy in architectural design.

So in conclusion, the nature of privacy in the space is as an effort to control, free yourself and protect your identity on his group. All groups developing privacy statement as control access to them from the others in several ways. The space (space) played the role of active on human interaction. As Almant stated, use of space may consist of as a determining factor for the person and for human behavior (Canter, 1974).So it can be received one of the main rules of human behavior in is to control the quality and quantity of interaction where a person takes part.

\section{Results and Discussion:-}

The since of the beginning of human emergence on earth, it takes a way to build in order to form and maintain human existence in mastering various technologies. Man finds himself not only enjoy greater convenience but also face a significant controversy and complexity. The humanity is understood as individuals who try to prove themselves, entering the process of participation by becoming members of the public and gain the ability to live together. Therefore humans became part of the cycle of change and transformation.

The Research results in investigating the concept of privacy in traditional houses at the change of habitus fisherman become indigenous farmers in Sentani. The concept of privacy is examined on the basis of historical reference year 1903, existing fisherman currently (Ayapo Village) and existing farming (Kehiran Village), based on the research method of model analysis. The model analysis of where the starting point of the analysis process on one of the starting points (based on a historical reference in 1903) is a traditional environment that has cultural characteristics to identify and understand the changes will be obtained two things. The first, changes in the environment have a set of characteristics that reduce the congruent with the core elements of culture (main). This was the findings of what's left of the traditional environment. Second, the new characteristics of both the environment and the culture can be found. Both models analysis comes together, so synthesis or syncretism can be discussed before (Rapoport and Hardie, 1983a).

In historical search, found the privacy of indigenous Sentani in 1903 has a concept of space that forms a defensive space. As Roscoe (2008) suggests, in New Guinea, the settlement fortress serves to deter attackers by using some obstacles to slow the enemy's arrival, increasing the likelihood that the entrants will see, thereby reducing their 
chances of defending elements in their environment. This tactic of depends on their success during the day and the problem is that in Papua the period of most settlement is needed. The defense and security system is located in the Obe house, where the Obe house is where the young men as the customary army, the warlord (the tribe chief of war) and the ultimate power of Ondofolo. In addition to the security orientation and protection system, the traditional houses of Imae have a security system on open-windows to view and observe the outside environment from village security disturbances. The imae house has a large room whose entire activity has no space boundaries. The privacy of the space formed at Imae's house, how the behavior in a community can control the visual, auditory, and olfactory power in carrying out the activities that make up the privacy. The Imae house does not have clear boundaries but the inhabitants can understand where the limits of space that can be used or used do not violate the privacy of other behaviors.
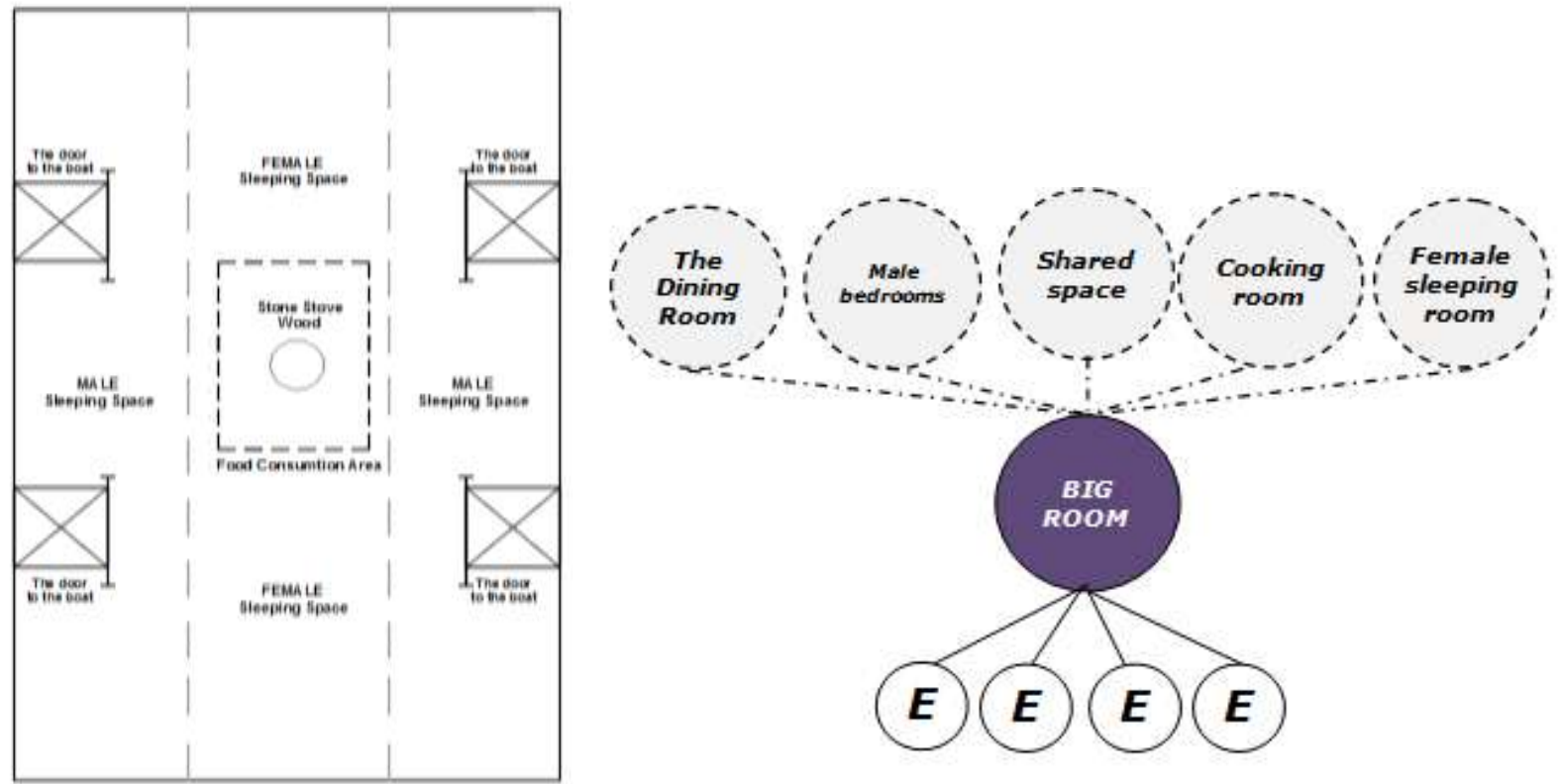

Figure 01:- Interpretation of Plan and Organization of Space In Imae House 1903 at Sentani Lake (Author, 2017).

The imae house form is closed, with large space as the main hall. The large room with the division of the men and women bedrooms as a privacy activity depicted by women is located in the middle of the room and the men are on the edge of the house. The activity within the home is connected to the exit access as the anticipated security of the occupants as stated by Altman (1975), privacy is a social unit that can be described either in the relationship between individuals and individuals, individuals with social groups or social groups with other social groups. The privacy that occurs in Imae's house is the privacy associated with a group of families in Imae's house. As Sande (1907) there is an open space in the house and there is a large fireplace located in the center of the room and the room is intended for family members who are married and close to the fireplace. The bedroom between the rooms is limited only by a wall made of woven sago leaves. The window made of straw can be lifted and supported by a small stick and women can see the visit or the arrival of strangers.

The concept of privacy formed in the house of Imae of Sentani indigenous in 1903 was formed from the influence of three elements tradition namely privacy as a defensive and controlling the visual, hearing and smell, Sarwono (1992) privacy is a desire or inclination in a person not to be disturbed loneliness.

The described in Figure 02 below. 


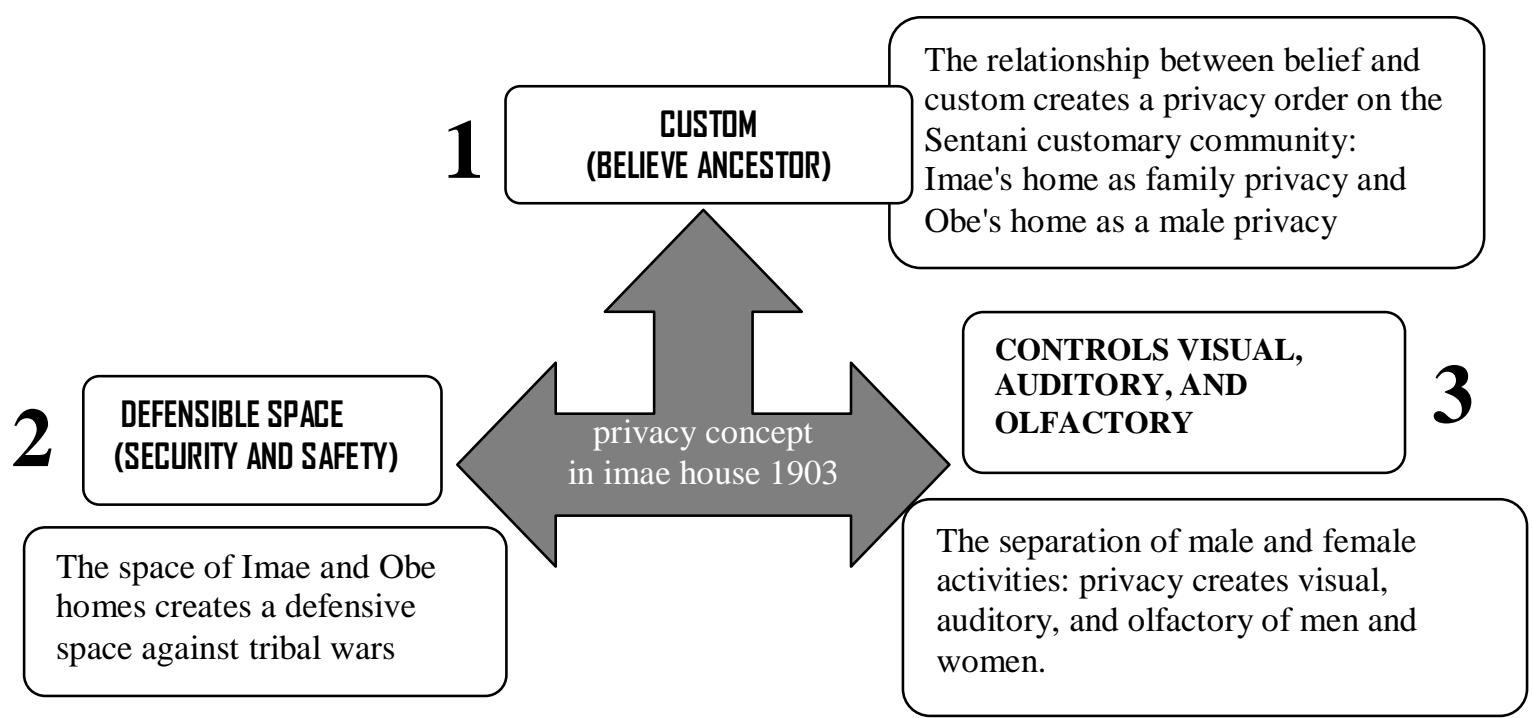

Figure 02:- The Concept of Privacy Space of Sentani Custom in 1903 (Author, 2017)

The concept of defensive space formed on indigenous peoples in 1903 is the privacy of indigenous peoples' behavior toward ancestral spirits. The concept of defensive space is a concept that is formed from traditional culture as the belief of indigenous peoples ( the spirit of ancestors), and cultural norms. The customary norms in belief in the spirit of ancestors and customs are described as a mechanism of behavior and environment, as Altman says two types of privacy governing mechanisms are the behavioral and environmental mechanisms. Behavioral mechanisms include verbal and nonverbal behaviors and are influenced by sociocultural factors. The mechanism of cultural behavior of indigenous peoples Sentani is influenced by socio-cultural factors that change in the community environment in shaping behavior in the physical environment of traditional houses. In the context of habitus, the special meaning of indigenous peoples' traditional settlements in 1903, the habitus formed in the built environment, constituted a space for the protection of indigenous peoples or their groups from external intervention. The habitus of indigenous peoples that provide space for protection appears to be based on the ways in which communities and indigenous peoples 'own ways of adapting to indigenous peoples' sociocultural experiences in defending the built environment with spontaneity in a strong

The concept of privacy found in the existing fisherman in Ayapo village revealed in beliefs to the ancestors began to decrease with the presence of a religion of credibility that became public confidence. The entry of Christianity the changed of concept privacy in indigenous Sentani peoples. The customs and norms of the Sentani people's of the cultural customs go hand in hand and more principally believe in God Almighty, this is demonstrated in the way of life, social interaction of everyday life and behavioral norms. The trust in God is an important aspect of regulating family privacy. The regulating privacy within the customary family creates a good quality of life of the traditional society in the use of space, a positive environment between the community and customs, the value of privacy and education for its inhabitants.

This is apparent in the case study at Pulalo house inhabited by six heads of households, indicating the privacy space in each family head is set in the rooms and kitchen area as the privacy area, each shown in Figure 03. 


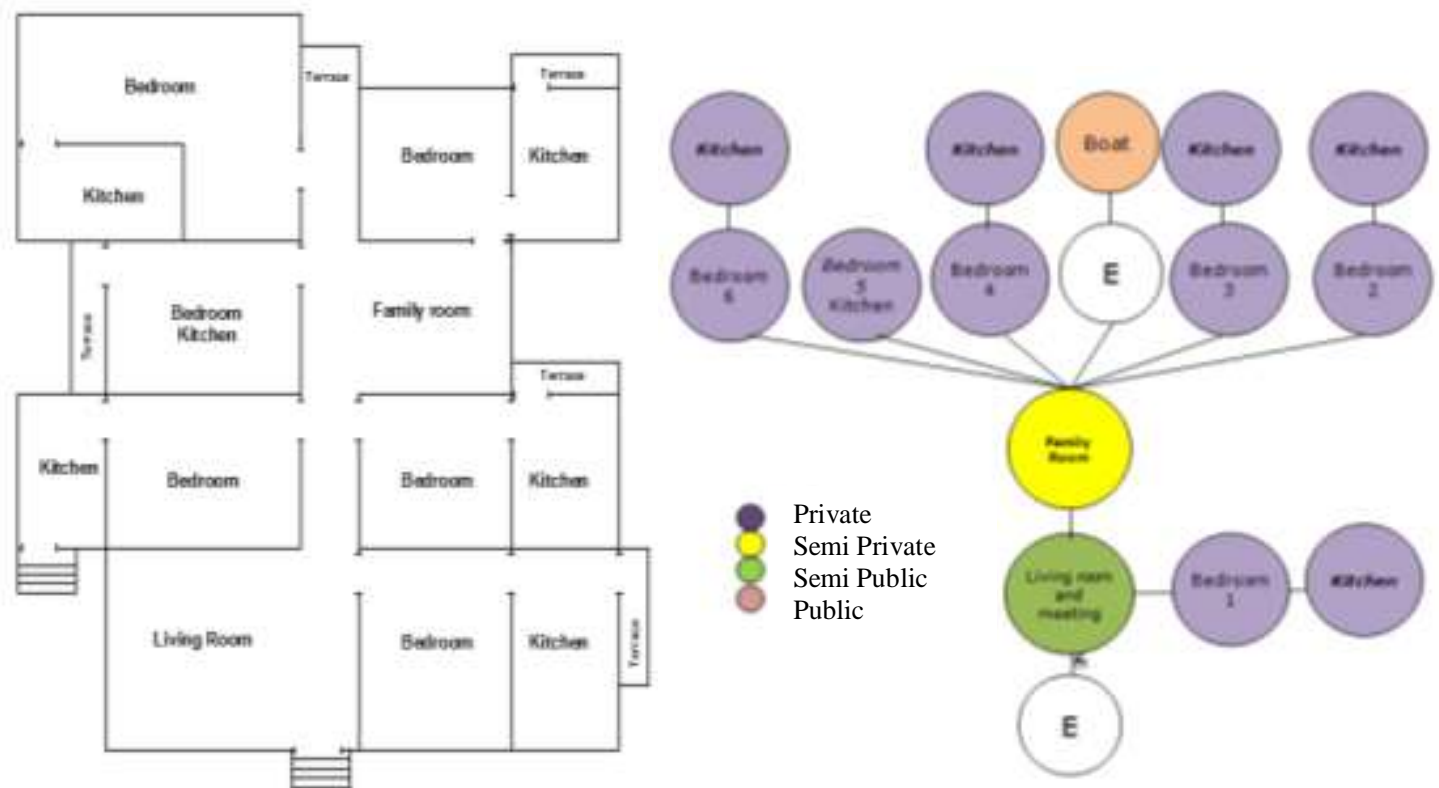

Figure 03:- Plan And Room Organization of Fisherman's House In Ayapo Village (Survey, 2016)

The visual privacy regulates the mechanisms identified from the survey study and the case includes the physical elements and behavioral norms. The private visuals on Imae house use an architectural element of curtains and doors that limit the space between heads of the chamber (room and kitchen) into visual privacy which governs the behavioral mechanism. Case studies show that windows and doors are usually left partially open to balance between the need for visual privacy and thermal comfort. The concept privacy that was formed in the Imae house of Sentani indigenous peoples in 1903 was formed from the influence of four elements namely custom and religion, security and safety, privacy elements, and male and female separators, described in Figure 04.

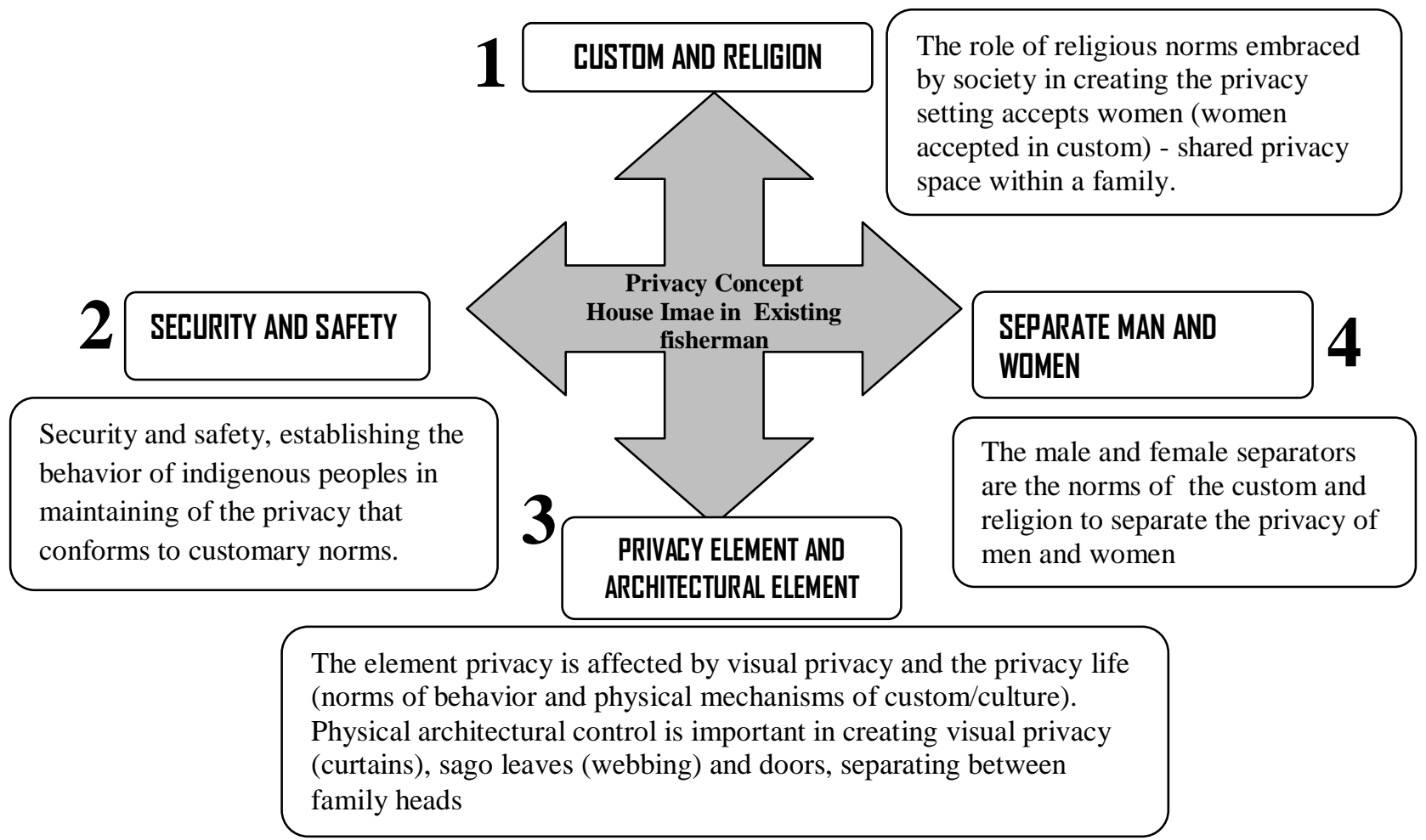

Figure 04:- The Community of Sentani Custom of the Privacy Concept in Fisherman Existing.

(Source: Author, 2017) 
In the concept of privacy in the fisherman house in Ayapo experiencing a change of concept that was originally the norm of belief to the spirit of the ancestors and religion is described as a mechanism of behavior and environment that revamp behavior of society. The behavioral mechanisms formed on home privacy include verbal and nonverbal behaviors and are influenced by sociocultural factors. The mechanism of cultural behavior of indigenous Sentani peoples is influenced by socio-cultural factors that change in the community environment in shaping behavior in the physical environment of traditional houses. In the context of the habitus of the fisherman community in Ayapo village, the special meaning of the traditional settlement of indigenous peoples is the built environment that constitutes the built environment that protects the indigenous and the Christian. The habitus that changes from belief in the spirits of ancestors and ancestors continues to be the group's customary activities, but belief in God is a key element in the life of each indigenous people. The habitus of indigenous peoples helps how custom can become part of the belief in the Gods of indigenous people. It is apparent that indigenous peoples have a way of thinking and experience of having faith in God brought in the experience of socio-cultural life. The experiences and ways of the community in dealing with their Lord in their contextual environment coexist with traditional activities that are still ongoing until today.

In the change of fisherman habitus to be a farmer in the village of Kehiran reveals that belief in the ancestors began to disappear and religion became the main belief in shaping cultural norms, the way of life, social interaction of daily life and behavioral norms become an important aspect of managing privacy in the family. Thus, the applied religious beliefs create a better quality of life for traditional society, the use of space, a positive environment between the community and customs, the value of privacy and education for its inhabitants. In traditional farmhouse houses privacy, semi-private and public spaces show behavioral restrictions on homes for parents, children, and daughters. In the observation of privacy in traditional fisherman's houses indicate that the way of life, social interaction of daily life and norms of indigenous people's behavior consistent with customary norms with families on the beliefs of the Sentani indigenous people beliefs and religions from the norms of community behavior and growth efforts. The findings in space zoning and governing privacy that occurs in indigenous peoples look more toward privacy in shaping the mechanisms of behavior of both individuals, families, and restrictions on the domain of women at home.

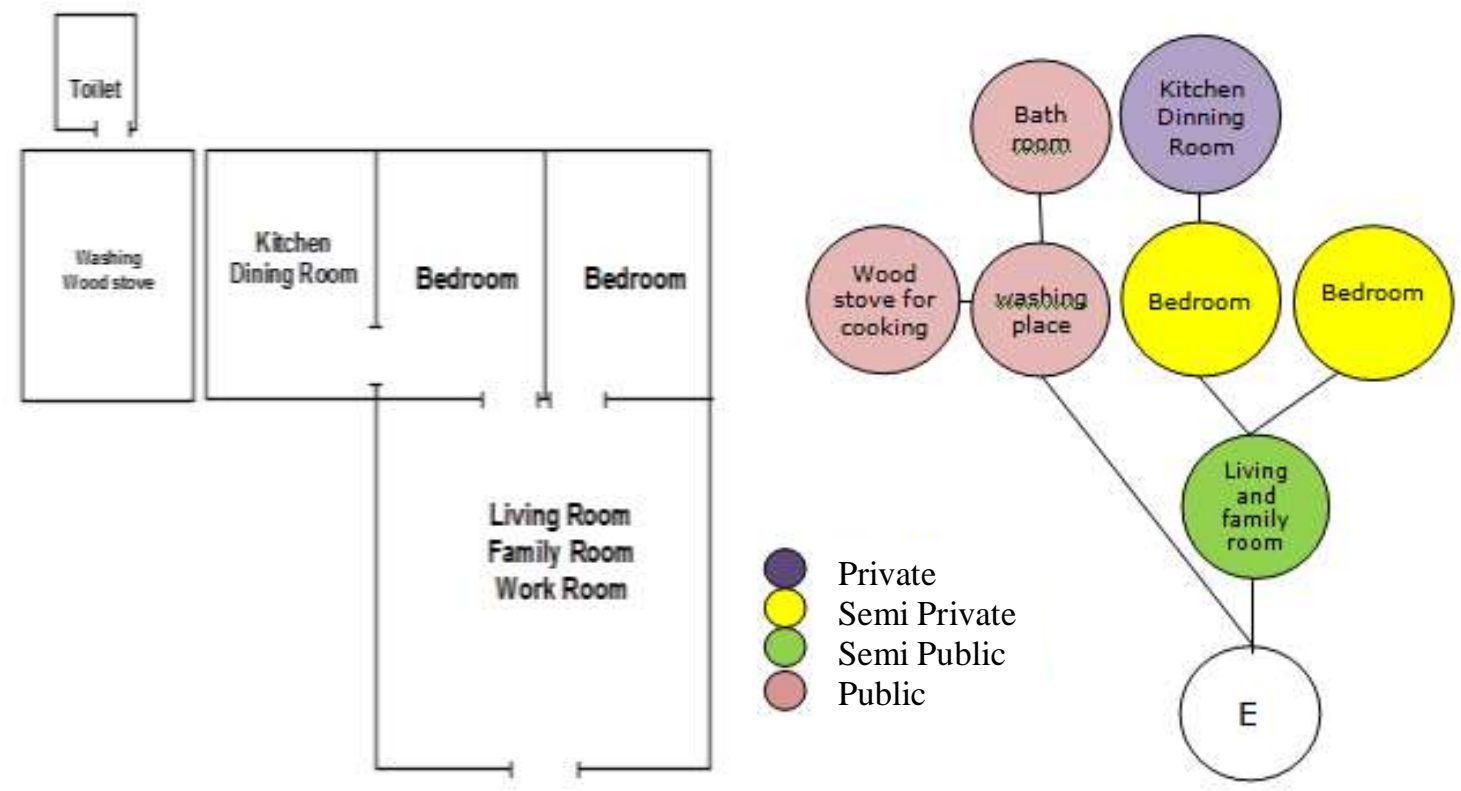

Figure 05:- The Plan and Organization of Spatial Spaces in Kehiran Village (Survey, 2016)

The Visual privacy on farmers' house on mainland Sentani, using the architectural elements of curtains, doors, and windows to limit the space between family members. The concept of privacy formed at Imae house of Sentani indigenous peoples in 1903 was formed from the influence of three elements namely religion, security and safety and element privacy and architectural components, described in Figure 06. 


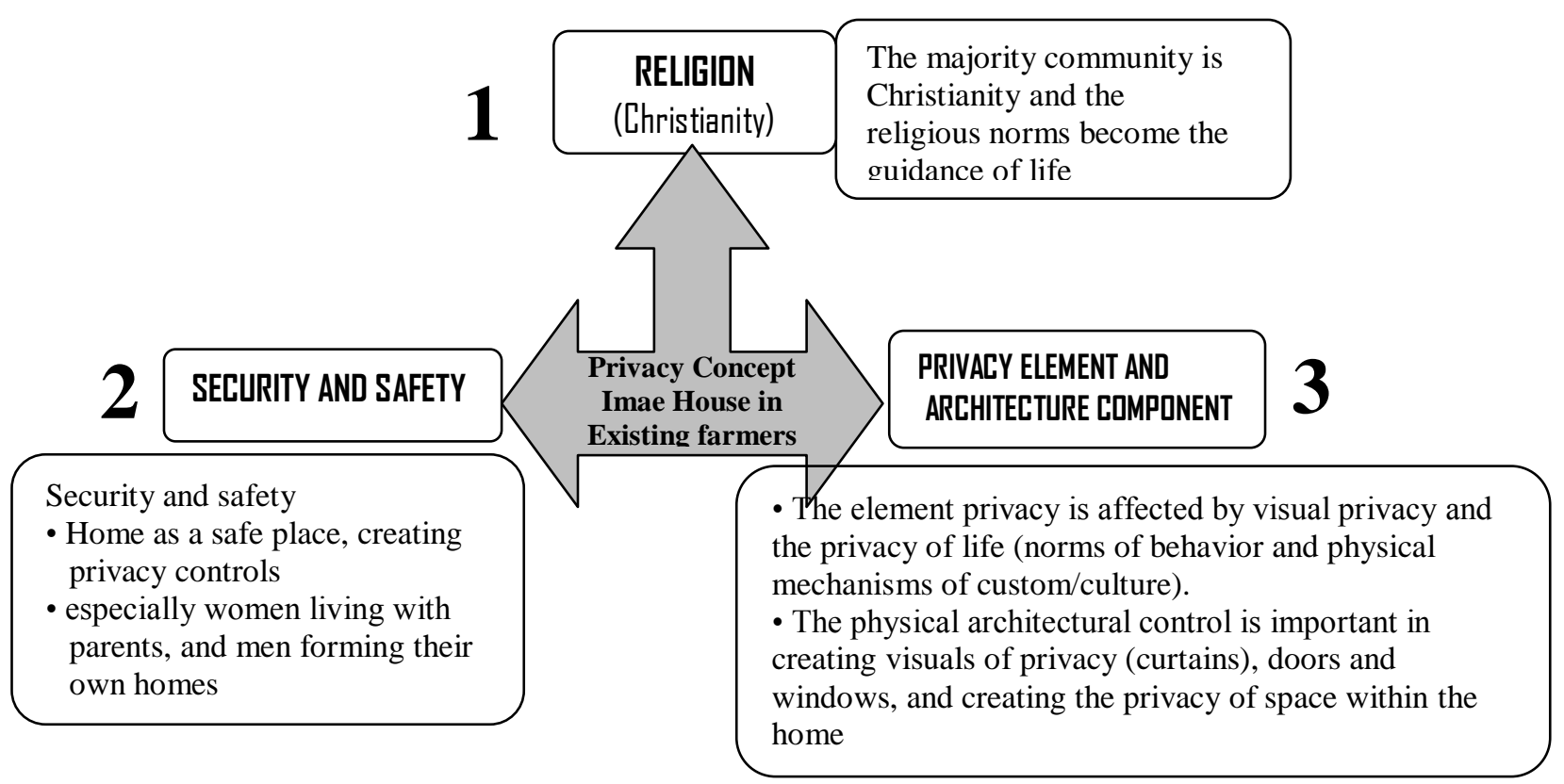

Figure 06:- The Community of Sentani Custom of The Concept Privacy in Farmers Existing. (Author, 2017)

In the concept of farmers' privacy in Kehiran undergo a change of concept, from which initially consists of four transformed into three elements that affect the Religion (Christianity), security and safety and privacy elements (architectural component). The privacy space formed in the farmhouse gives the means of an effort to effectively control access to emphasize the closeness and openness that lead to the development of human behavior and moral growth as Newell (1995). The religious norms (religions of Christianity) that prevailed in the Sentani customary community, changed the privacy of the farmers' homes. The change of space of privation to the safety and comfort of the occupants and the use of the elements of privacy and the architectural component in forming the privacy space, which is a regulatory process that changes according to needs and arrangements (Altman, 1977), which involves the ability of individuals to control the permeability of interpersonal boundaries. In the context of habitus, the special meaning of traditional settlements in the farming habitat of the Sentani mainland today, the habitus formed is the built environment that shapes the society's thinking for the welfare of their family (nuclear family). The habitus farmers still provide protection against indigenous peoples but not a major element. Habitus of farmers in indigenous people helps confidence in the God of indigenous people is a key element in belief in God (Christian). This is evident from the background of indigenous peoples who have faith in God to be the guides of life brought to the experience of sociocultural life in their contextual environment.

The change privacy to the fisherman habitus to farmers is a way of controlling the boundaries between the personal and cultural environment in creating social relations regulation and behavioral mechanisms, in which accessibility is uniquely controlled, both physically, psychologically and socially. The traditional Sentani society is part of how to create privacy becomes important in the process of achieving privacy, when the physical environment does not provide the desired privacy. The physical and behavioral arrangements of indigenous peoples affect the concept of privacy. The quality of the environment as the built environment is the determinant of behavior in which behavioral adaptation is a spontaneous response to constraints in the environment as Archea, (1977) and a good environment are determinants of behavior and as an extension of behavior according to Altman (1977). The Kehiran residence establishes the concept of good privacy through the mechanisms of behavior and the environment of the family, which provides a visual level of personal comfort. The social behavior within the ward of the Kehiran village forms the privacy that is part of the interdependence that is intertwined, where changes in one aspect will have a direct influence on others, and the change of privacy of the Sentani indigenous peoples is happening in a better direction in creating behavioral adaptations that conform to the norm of Christian religion of the community. 


\section{Conclusion:-}

The privacy concept formed on the Sentani indigenous peoples is a way of separating gender in spatial arrangements, forming elements of privacy, architectural design components, security and safety in the development of community behavior. The community behavior that is formed from the cultural norms of indigenous Sentani peoples in defining privacy changes. The changes in privacy caused by the influence of public confidence and belief, and how privacy creates the individual's security and ability to control the boundary permeability between individuals.

The changes of fisherman habitus to farmers on indigenous communities Sentani caused changes in the use of space as a privacy space. The changes in the concept of privacy influenced people behavior in the use of space in improving the quality of life. The changes in the concept of privacy influenced the ways of society and its experience in understanding the new environment in adapting to belief in God and Custom. The understanding that privacy elements and architectural elements such as visual privacy and curtain elements, windows, doors, and walls provide the direction of privacy into consideration in shaping the built environment to improve the quality of life among the Sentani indigenous people. The Privacy as an access control in emphasizing the closeness and openness that may lead to the development of human behavior as required by Altman and Chemers (1984) and privacy as a temporary condition in the separation of the public domain aspects of ownership and responsibility in making alternative choices in accordance with the changing nature of conditions with respect to segregation public domain and behavioral and moral development (Newell, 1995). The changes concept of privacy in indigenous peoples Sentani cause the changes in form of homes. In the habitus of fisherman and farmers, the privacy of occupancy undergoes changes that are influenced in addition to the family structure, privacy, and basic needs. The changes influence of the occupation of identity, social relations of the residents and organization of space.

Note:

Obe: The house of activities of indigenous activities; Imae: the chief house of the tribe; Ondoafi / Ondofolo: the highest customary leader; Khoselo: the head of the clan group.

\section{References:-}

1. Abdul-Rahim A (2014), The Influence of Culture and Religion on Visual Privasi, Asian Conference on Environment-Behaviour Studies Chung-Nag University, Seoul, S. Korea, 25-27 August 2014.

2. Altman, I ; Chemers, Martin (1984), Culture and Environment, First published by Cambridge University.Press.

3. Altman, I, Chemers, M. M. (1980). Culture and Environment (The Brooks/Cole basic concepts in environment and behavior series). Cambridge University Press.

4. Altman, I, Vinsel, A and Brown, B. B. (1981). Dialectic Conceptions in Social Psychology: An Application and Privacy Regulation, Advances in Experimental Social Psychology, 14, 107-157.

5. Altman, I. (1977). Privacy Regulation: Culturally Universal or Culturally Specific? Journal of Social Issues, 33, 66-84.

6. Besim, S. H. (1986). Arabic-Islamic Cities: Building and Planning Principles. New York: KPI Limited.

7. Bourdieu, P. (1977). Outline of a Theory and Practice. Cambridge: Cambridge University Press.

8. Bourdieu, P. (1989) 'Social space and symbolic power', Sociological Theory,

9. Bourdieu, P. (2002). "Habitus." In Habitus: A Sense of Place, edited by Jean Hillier, and Emma Rooksby, 2733. Burlington: Ashgate Publishing Limited.

10. Fahey. T. (1995). Privasi and Family: Conceptual and Empirical Reflections. Sociology: Journal of the British Sociology Association, 24(4), 687-702.

11. Faqih, Muhammad (2005), Domestic Architecture and Culture Change, Re-ordering the Use of Space in Madurese Housing. Thesis Doctor of Philosophy University of Newcastle

12. Groat, L. \& Wang, D. (2002). Architectural Research Methods. New York: John Wiley\& Sons. Inc.

13. Margulis, S. T. (2003). Privacy as a social Issue and Behavioral Concept. Journal of Social Issues, 59(2), 243 261.

14. Newell, P. B. (1994). A System Models of Privacy. Journal of Environmental Psychology, 14 (1), $65-78$.

15. Rapoport, A (1969), House Form and Culture, Prentintice Hall,Inc, Englewood Cliffs, New York.

16. Rapoport, A (2005), Culture, Architecture and Design, Locke Science Publishing Company, Inc, Chicago

17. Rapoport, A dan Hardie (1983) 'Development, culture change and supportive design', Habitat International. 
18. Rapoport, A, dan Hardie, Graeme (1991), "Cultural change analysis: Core Concepts of Housing for The Tswana” dalam Housing The Poor in The Developing World, eds. Tipple, Graham A. dan Willis, Kenneth G., Routledge, London.

19. Razali NHR dan Talib A, (2013), The Concept of Privasi and the Malay Dwelling Interior Space Planning, AMER International Conference on Quality of Life Holiday Villa Beach Resort \& Spa, Langkawi, Malaysia, 68 April 2013.

20. Suprijanto, Iwan (2008), Karakteristik Spesifik, Permasalahan dan Potensi Pengembangan Kawasan Kota Tepi Laut/Pantai (Coastal City di Indonesia, Proceeding - Studi Dampak Timbal Bali kantar Pembangunan kota dan Perumahan di Indonesia dan Lingkungan Global.

21. Waterson, R. (1993) The Living House: an Anthropology of Architecture in South-East Asia. Oxford University Press

22. Westin, A. F. (1967). Privacy and Freedom. New York: Atheneum. 